\title{
A simplified test for preference rationality of two-commodity choice
}

\author{
Samiran Banerjee • James H. Murphy
}

Published online: 13 June 2008

(C) Economic Science Association 2008

$\begin{aligned} & \text { Erratum to: } \text { Exp Econ (2006) 9: 67-75 } \\ & \text { DOI 10.1007/s10683-006-4313-6 }\end{aligned}$

The affiliation of James H. Murphy was incorrect in the above-referenced article. Please see below for the correct affiliation listing.

The online version of the original article can be found under doi: 10.1007/s 10683-006-4313-6.

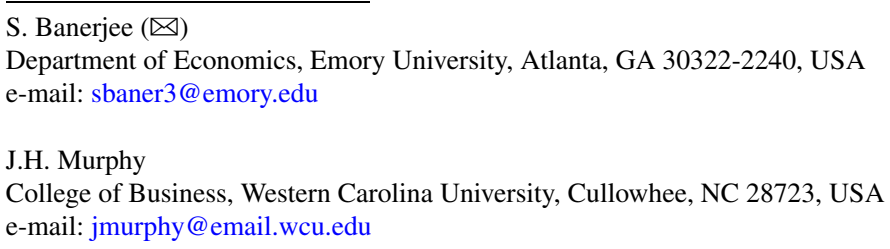

J.H. Murphy

Department of Economics, Richards College of Business, University of West Georgia, Carrollton, GA 30018, USA 